Original Article

\title{
Is Addition of GNRH Agonist to HRT Significant in Improving The Outcome in FTE Transfer Cycles : Randomized Study
}

\author{
Khalid M. Salama, Ibrahim I. Souidan
}

Department of Obstetrics and Gynecology, Faculty of Medicine, Benha University, Egypt

\begin{abstract}
Background: Despite the high number of frozen embryo transfer cycles being conducted, there is much debate about which protocol for endometrial preparation is ideal.

Aim: The aim of this study is detect the value of gonadotropin-releasing hormone agonist (GNRH-a) in the preparation of the endometrium regarding the cycle outcome.

Materials and Methods: One hundred forty women participated in the study. They were randomly divided into two groups; group 1 and group 2. The patients of group 1 received injection of GnRH-a triptoreline $(3.75 \mathrm{mg})$ on the day-21 of the menstrual cycle proceeding the replacement cycle. Both groups received exogenous estradiol starting from the second day of the cycle then the dose was increased incrementally till the endometrial thickness was $\geq 8 \mathrm{~mm}$ or more. Progesterone was given to the patients before embryo transfer and continued thereafter. Twelve days later, serum pregnancy test was done and if positive, transvaginal ultrasonography was done two weeks later for detection of embryo cardiac activity.

Results: Both groups showed no statistically significant differences regarding demographic, clinical and laboratory data and their relations to pregnancy. Serum pregnancy tests detected chemical pregnancy that was confirmed by transvaginal ultrasonography at 6 weeks gestation in only $49.3 \%$ of women (clinical pregnancy rate $=49.3 \%$ ). Only six women aborted at $8-12$ weeks gestation (ongoing pregnancy rate $=45 \%$ ). There were no significant differences between both groups regarding the clinical outcome.

Conclusion: Addition of GNRH-a to HRT to prepare the endometrium in the FTE transfer cycle had no significant effect on the clinical outcome.
\end{abstract}

Key Words: FTE transfer, GNRH, HRT

Received: 22 May 2020, Accepted: 06 December 2020

Corresponding Author: Khalid M. Salama, Department of Obstetrics and Gynecology, Faculty of Medicine, Benha University, Benha, Egypt, Tel.: 01225861026, E-mail: dr.khalidsalama@gmail.com

ISSN: 2090-7265, February 2021, Vol.11, No. 1

\section{INTRODUCTION}

Successful implantation depends on synchronicity between the developmental stage of the embryo and the prepared endometrium ${ }^{[1]}$.

The procedure of freezing and thawing is used for storage of embryos and their transfer in non-hyper stimulated cycle. The improvement of laboratory conditions leaded to progressive increase of FTE transfer cycles $^{[2]}$. Furthermore, the pregnancy rate in FTE transfer is more than following fresh $\mathrm{ET}^{[3,4]}$.

Various protocols of endometrial preparation have been described. They included pure natural cycle (NC), with detection of $\mathrm{LH}$ in blood or urine, natural modified cycle (nMC) in which HCG is administered, artificial cycle with estradiol (E2) and progesterone (p4) with or without addition of gonadotropin releasing hormone agonist (GNRH-a) and lastly low doses of gonadotropins. However, there is still a debate which protocol is ideal ${ }^{[5]}$.

Each of these methods has advantages and disadvantages. Natural cycles allow the women to transfer without treatment, but its problem is scheduling the patient's activity in an IVF unit because the date of transfer is dictated by the patient's ovulation and this method cannot be offered to women with irregular cycles. Artificial cycles resolved these two problems and are the most commonly used approach worldwide. Stimulated cycles are associated with higher cost, risk of side effects of the treatment. In spite of this discrepancy, the pregnancy and live birth rates were comparable in all methods ${ }^{[6]}$.

Currently most IVF units use GNRH-a in the artificial preparations of the endometrium to induce pituitary down 
regulation to prevent spontaneous ovulation. However, this method is costly and has the risk of the hypo estrogenic state that may lengthen the preparation of the endometrium. All recent studies compared the artificial preparation with or without pituitary suppression and found no significant differences ${ }^{[7]}$. The optimal protocol is the most efficient and cost effective and associated with the lowest burden on the patients $^{[8]}$

\section{AIM OF THE WORK}

The aim of this study is to detect the value of addition of GNRH-a in the artificial preparation of the endometrium regarding the cycle outcome.

\section{PATIENTS AND METHODS}

Patient data: This randomized study was conducted at Dar El-Teb Hospital, Dokki, Giza, Egypt, during the period from December 2017 till October 2019. Approval of the Local Ethical Committee was obtained from all participants in the study. One hundred forty women participated in the study with the following criteria; age (22-40 years) and BMI (less than $36 \mathrm{~kg} / \mathrm{m} 2$ ).

Exclusion criteria: Gross uterine and tubal pathology, endometrial thickness $\leq 7 \mathrm{~mm}$ at the time of embryo transfer, poor quality of embryos after thawing, and refusal to participate in the study at any step of the cycle.

Randomization and Grouping : Randomization of all the women was conducted by using sealed envelopes that contain cards prepared by a blinded assistant and cards were chosen by the patient herself. They were divided into two groups (group 1 and group 2.The patients of group 1 received injection of GnRH-a triptoreline (Decapeptyl, Ferring Pharmaceuticals Ltd., Wittland, Germany; $3.75 \mathrm{mg}$, subcutaneous injection) on the day-21 of the menstrual cycle preceding the replacement cycle.

Study protocol : The classic slow freezing and rapid thawing protocol of Testart ${ }^{[9,10]}$ was applied using a programmable freezer (Planer; Middlesex, UK) and embryo freezing and thawing kits (Irvine Scientific, Santa Ana, CA, USA) were used. After thawing, all embryos were transferred to culture in vitro for 2 days $^{[11]}$. On the third day, embryos in G1 and G2 grade were defined as good quality embryos and 1-3 embryos of good quality were transferred, while poorer grade embryos were discarded $^{[12]}$.

All women received the same hormone replacement therapy in the form of estradiol valerate (Progynova $2 \mathrm{mg}$, Bayer Schering Pharma, UK). The estradiol was started on day-2 of menses of replacement cycle as a daily dose of $2 \mathrm{mg}$ and the doses were increased incrementally till endometrial thickness was at least $8 \mathrm{~mm}$. Endometrial thickness was detected by transvaginal ultrasound (Sonoline Prima 7.5 MHz, Siemens). Then, oral micronized progesterone (300 $\mathrm{mg}$ per day (progest, micronized progesterone $100 \mathrm{mg}$, Technopharma, Egypt, for pharco pharmaceuticals, Amriya, Alexandria) was given for two days before cleaved embryos transfer and for four days before blastocyst transfer and continued thereafter. Twelve days later to embryo transfer, serum pregnancy test was done and if positive, the clinical pregnancy was confirmed by TVS for detection of gestational sacs and embryo cardiac activity. Antenatal care of the pregnancy was done elsewhere because our unit is specialized for IVF only.

Primary outcome: The clinical pregnancy was detected by TVS at 6 weeks gestation (gestational sacs and embryo cardiac activity). The ongoing pregnancy was detected by abdominal ultrasound at 12 weeks. Detection of chemical pregnancy that was defined as a positive pregnancy test but the pregnancy did not appear on ultrasound examination.

Sample size estimation: The sample size was calculated using Open Epi according to the following; the percentage of pregnancy among GNRH group was $65.5 \%$ and among HRT group was $42 \%{ }^{[13]}$ so, at power of study $80 \%$ and CI $95 \%$. The sample size was calculated to be 140 cases divided into two equal groups.

\section{STATISTICAL ANALYSIS:}

The collected data were computerized and statistically analyzed using SPSS program (Statistical Package for Social Science) version 25.0. Qualitative data were represented as frequencies and relative percentages. Chi square test was used to calculate difference between qualitative variables. Quantitative data were expressed as mean $\pm \mathrm{SD}$ (Standard deviation).Independent $\mathrm{T}$ test and Mann Whitney test was used to calculate the difference between quantitative variables. The threshold of significance is fixed at 5\% level ( $P$-value), $P$ value of $>0.05$ indicates non-significant results, $P$ value of $<0.05$ indicates significant results and $P$ value of $<0.01$ indicates highly significant results.

\section{RESULTS}

From 146 women consented to participate in the study, 6 women were excluded from the work; 2 women were having poor endometrial thickness, 2 women were having embryos of poor quality, and the remaining 2 women refused to participate in the study (Fig.1). 
Only one hundred forty women completed the study. Both groups showed no statistically significant differences regarding demographic, clinical and laboratory data and their relations to pregnancy (Table 1).

After thawing, assessment of embryos for transfer was done, 244 embryos were transferred to all women with a mean number 1.74 embryo per woman.
Serum pregnancy tests detected chemical pregnancy that was confirmed by TVS at 6 weeks gestation in only $49.3 \%$ of women (clinical pregnancy rate $=49.3 \%$ ). Only six women aborted at 8-12 weeks gestation (ongoing pregnancy rate $=45 \%$ ). There were no significant differences between both groups regarding the clinical outcome (Table 2).

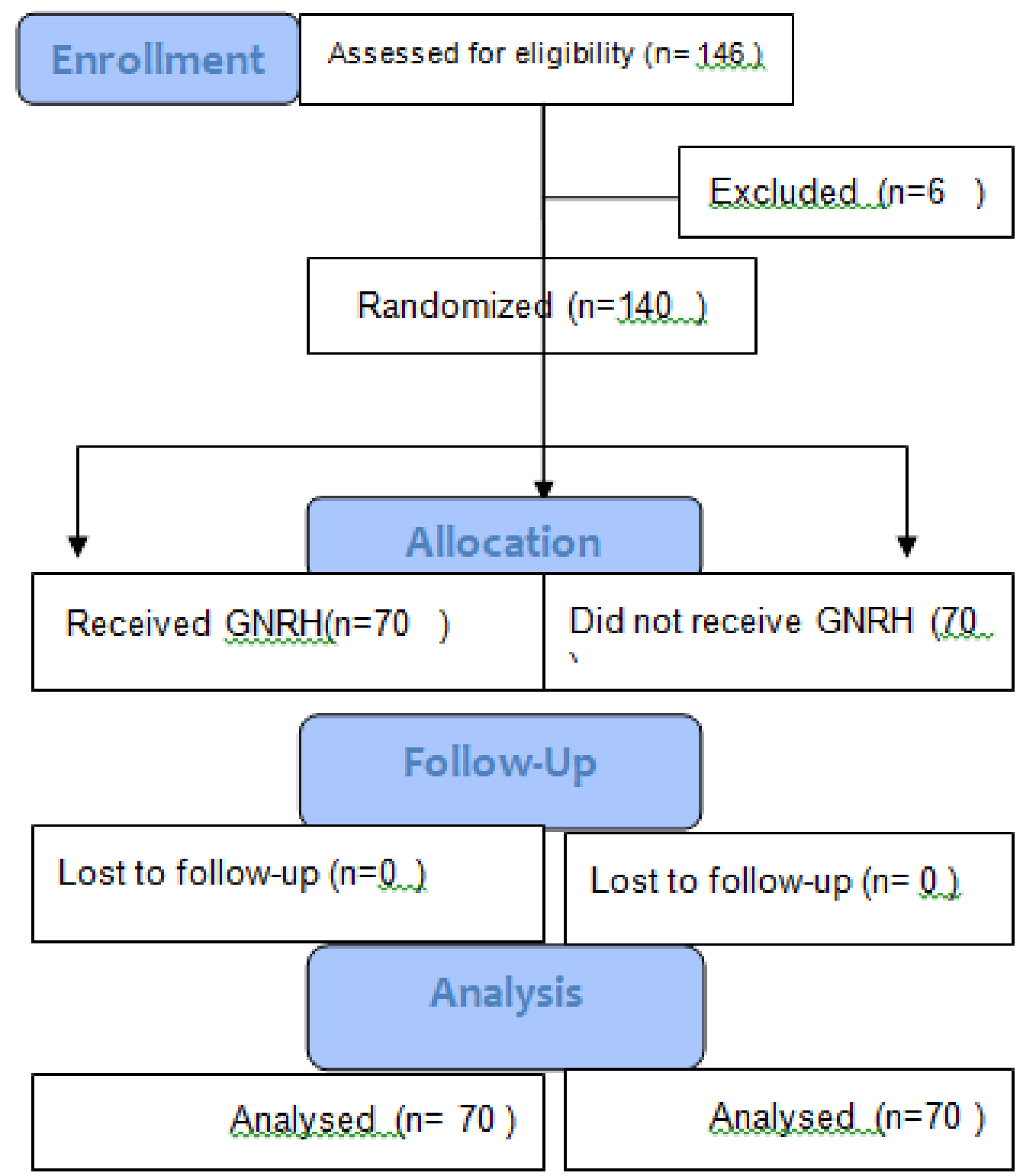

Fig. 1 : Consort flow diagram 
Table 1: Shows demographic, clinical and laboratory data and their relations to pregnancy

\begin{tabular}{|c|c|c|c|c|}
\hline Variable & $\begin{array}{c}\mathrm{HRT}+\mathrm{GNRH} \\
(\mathrm{n}=70)\end{array}$ & $\begin{array}{c}\text { HRT } \\
(n=70)\end{array}$ & Test & $P$ value \\
\hline Age (years) & $\begin{array}{c}30.33 \pm 5.65 \\
22-40\end{array}$ & $\begin{array}{c}30.79 \pm 6.16 \\
22-40\end{array}$ & $\begin{array}{c}\mathrm{t} \\
0.46\end{array}$ & $0.65 \mathrm{NS}$ \\
\hline BMI (Kg/m2) & $\begin{array}{c}30.41 \pm 23.20 \\
26-36\end{array}$ & $\begin{array}{c}31.2 \pm 2.91 \\
26-36\end{array}$ & $\begin{array}{c}\mathrm{t} \\
1.52\end{array}$ & $0.13 \mathrm{NS}$ \\
\hline Cause of infertility: & & & & \\
\hline Male factor & $16(22.9 \%)$ & $19(27.1 \%)$ & & \\
\hline Tubal & $16(22.9 \%)$ & $22(31.4 \%)$ & $\begin{array}{c}\chi^{2} \\
5.80\end{array}$ & $\begin{array}{l}0.12 \\
\mathrm{NS}\end{array}$ \\
\hline Decreased ovarian reserve & $28(40 \%)$ & $15(21.4 \%)$ & & \\
\hline $\mathrm{PCO}$ & $10(14.3 \%)$ & $14(20 \%)$ & & \\
\hline Previous fresh cycles & $59(84.3 \%)$ & $63(90 \%)$ & $\chi 2=1.02$ & $0.31 \mathrm{NS}$ \\
\hline Previous FET cycles & $10(14.3 \%)$ & $12(17.1 \%)$ & $\chi 2=0.22$ & $0.64 \mathrm{NS}$ \\
\hline Endometrial thickness & $\begin{array}{c}9.81 \pm 1.40 \\
8-12\end{array}$ & $\begin{array}{c}9.64 \pm 1.30 \\
8-12\end{array}$ & $\begin{array}{c}\mathrm{t} \\
0.75\end{array}$ & $0.45 \mathrm{NS}$ \\
\hline Duration of cryopreservation(month) & $\begin{array}{c}17.99 \pm 10.20 \\
5-36\end{array}$ & $\begin{array}{c}20.61 \pm 9.67 \\
5-36\end{array}$ & $\begin{array}{l}\text { MW } \\
1.05\end{array}$ & $0.29 \mathrm{NS}$ \\
\hline $\begin{array}{l}\text { Developmental stage of cryo preserved embryo } \\
\text { cleaved embryo } \\
\text { Blastocyst }\end{array}$ & $\begin{array}{c}(n=117) \\
50(42.7 \%) \\
67(57.3 \%)\end{array}$ & $\begin{array}{c}n=127) \\
69(54.3 \%) \\
58(45.7 \%)\end{array}$ & $\begin{array}{c}\chi^{2} \\
3.28\end{array}$ & $\begin{array}{l}0.07 \\
\text { NS }\end{array}$ \\
\hline
\end{tabular}

Data are presented as mean $\pm \mathrm{SD}$, median and ranges are in parenthesis; *: Significant $(p<0.05)$; **: Highly Significant $(p<0.01)$. 
Table 2: Shows outcome among the studied group

\begin{tabular}{|c|c|c|c|c|}
\hline Variable & $\begin{array}{l}\text { HRT+GNRH } \\
(n=70 \text { woman })\end{array}$ & $\begin{array}{c}\text { HRT } \\
(\mathrm{n}=70 \text { woman })\end{array}$ & Test & $P$ \\
\hline \multicolumn{5}{|c|}{ Total NO of transferred embryos(TTE): } \\
\hline 1 & $38(54.3 \%)$ & $32(45.8 \%)$ & $x^{2}$ & 0.58 \\
\hline & & & 1.10 & NS \\
\hline 2 & $17(24.3 \%)$ & $19(27.1 \%)$ & & \\
\hline 3 & $15(21.4 \%)$ & $19(27.1 \%)$ & & \\
\hline Mean NO of transferred embryos & $1.67 \pm 0.81$ & $1.81 \pm 0.84$ & $\mathrm{MW}=1.04$ & $0.30 \mathrm{NS}$ \\
\hline Chemical pregnancy & $38(54.3 \%)$ & $44(62.9 \%)$ & $\chi 2=1.06$ & $0.30 \mathrm{NS}$ \\
\hline Clinical pregnancy & $32(45.7 \%)$ & $37(52.9 \%)$ & $\chi 2=0.71$ & $0.40 \mathrm{NS}$ \\
\hline Ongoing pregnancy & $32(45.7 \%)$ & $31(44.3 \%)$ & $\chi 2=0.03$ & $0.87 \mathrm{NS}$ \\
\hline No of gestational sacs(IR): & $(n=32)$ & $(n=37)$ & $\chi^{2}$ & \\
\hline 1 & $10(68.8 \%)$ & $9(24.3 \%)$ & 0.41 & $0.52 \mathrm{NS}$ \\
\hline 2 & $22(31.3 \%)$ & $28(75.7 \%)$ & & \\
\hline IR & $54 / 117=46 \%$ & $65 / 127=51 \%$ & 0.62 & $0.43 \mathrm{NS}$ \\
\hline
\end{tabular}

Data are presented as mean $\pm \mathrm{SD}$, median and ranges are in parenthesis; *: Significant $(p<0.05)$; $* *$ Highly Significant $(p<0.01)$. 


\section{DISCUSSION}

The implantation of the embryo in FTE transfer depends on the synchronization between the prepared endometrium and developed embryo. The endometrial preparation may be artificially induced using exogenous estrogen with or without GNRH agonist ${ }^{[14]}$. This study compared this artificial endometrial preparation with or without previous pituitary down regulation. We found no significant differences between both methods regarding implantation, chemical, clinical and ongoing pregnancy rates.

Different methods were used to prepare the endometrium. The originally used methods were NC and $\mathrm{nMC}$, but due to complicated follow up (blood tests and serial US scans), artificial preparation by exogenous estrogen was' introduced. Others added GNRH a in an attempt to confirm non ovulation to improve the outcome, but no significant differences were detected ${ }^{[14]}$.

The transfer of frozen embryo must synchronize the ovulation in $\mathrm{NC}$ or after preparing the endometrium by E-P. The exogenous hormonal regimens improved the outcome when compared to $\mathrm{NC}$ but this improvement was not significant ${ }^{[15]}$.

Several studies either randomized or retrospective tried to compare both regimens of artificial preparation and found no significant differences between addition of GNRH and non-addition to exogenous steroids regarding the cycle outcome ${ }^{[16]}$.

Different doses and method of administration of exogenous steroids were used. In a study of Simon et $a l . .^{[17]}$, they used fixed daily doses of estradiol $(6 \mathrm{mg})$ to women not receiving GNRH-a; while the women who received GNRH-a were taken $4 \mathrm{mg}$ of estradiol. Also, they used micronized progesterone tablets $300 \mathrm{mg}$ three times vaginally. Other study used transdermal estrogen patch in a fixed dose with or without previous down regulation. In our study, we used incrementally increased doses of estrogen and oral micronized progesterone tablets 300 mg daily. The results were similar to those reported by Simon et al. ${ }^{[17]}$ and Dal Prato et al. ${ }^{[18]}$.

In this study, we started the estrogen in a low dose then increased gradually; while Simon et al. ${ }^{[17]}$ started by a high fixed dose $6 \mathrm{mg}$ whereas Pattinson et al. ${ }^{[19]}$ started from the second to fifth day of the cycle and maintained by low fixed doses $2 \mathrm{mg}$.

Non-physiologically high estradiol levels in artificial cycle was claimed to cause endometrial damage and variations in the implantation window ${ }^{[20]}$. If the claim was taken into account, lower pregnancy rates would be expected.
Hill et al. believed that without the use of GNRH agonist, early endometrial preparation with estrogen at 1-2 of the menstruation was sufficient for suppression of ovulation and when given in step up manner not fixed was more physiologic and was more sufficient for endometrial maturation and subsequently embryo implantation.

Glujovsky et al..$^{[21]}$ believed that the appearance of dominant follicle did not affect the outcome of FTE transfer cycles when the endometrium was prepared without previous down regulation.

Zhihong et al. ${ }^{[22]}$ believed that the endometrium to be receptive needs thick endometrium $5-8 \mathrm{~mm}$ for optimal development of progesterone receptors and endometrial transformation. Also, they stated that without the use of GNRH agonist only the US scan not E2 level on progesterone initial day can help to predict the cycle outcome.

Pretreatment with GNRH-a had the advantage of inhibition of spontaneous ovulation and cancellation of the cycle. But many studies compared artificial endometrial preparation with and without GNRH-a and found no significant difference on the cycle outcome $^{[22,23,14]}$.

Some studies used different forms of GNRH-a and found no significant difference on the cycle outcome ${ }^{[23,18]}$.

Kalem, et al. $^{[24]}$ concluded that early luteinization may exist in $5 \%$ and complete down regulation with GNRH-a cannot be guaranteed in artificial cycles .The only detected positive factor affecting the pregnancy rate was the endometrial thickness which was determined by estrogen ${ }^{[25,26,27]}$.

Previous studies concluded that the previous down regulation was not needed for endometrial preparation in FTE transfer cycle ${ }^{[17,28]}$.

Programmed cycle without GNRH-a pretreatment was more convenient to the patient and medical staff and resulted in the same outcome at a lower cost . The woman still had the option of choosing the desired cycle to transfer and the used medication was more comfortable ${ }^{[7]}$. In clear, the program without GNRH-a may be preferred because it was simple and of low cost especially in developing countries.

\section{CONCLUSION}

Addition of GNRH-a to HRT to prepare the endometrium in the FTE transfer cycle had no significant effect on the clinical outcome.

ETHICS APPROVAL AND CONSENT TO PARTICIPATE 
The study was approved by the Local Ethical Committee of Benha University Hospital and the reference number is not applicable. Written informed consent was obtained from each participant before the study.

\section{CONFLICT OF INTEREST}

There are no conflicts of interests.

\section{REFERENCES}

1. Saupstad M, Freiesleben NLA, Skouby SO, Andersen LF, Knudsen UK, Petersen KB., Husth M, Egeberg A, Petersen MR, Ziebe S(2019) Preparation of the endometrium and timing of blastocyst transfer in modified natural cycle frozen-thawed embryo transfers (mNC-FET):a study protocol for a randomised controlled multicentre trial. BMJ Open;9:e031811. doi:10.1136/bmjopen-2019-031811.

2. Gurgan T, and Demirol A (2004) Why and how should multiple pregnancies be prevented in assisted reproduction treatment programmes? Reprod Biomed Online 9:237-44.

3. Shapiro BS, Daneshmand ST, Garner FC, Aguirre M, Hudson C, Thomas S. (2011) Evidence of impaired endometrial receptivity after ovarian stimulation for in vitro fertilization: a prospective randomized trial comparing fresh and frozenthawed embryo transfer in normal responders. Fertil Steril. 96(2):344-8.).

4. Aziz AR (2015) Natural versus artificial cycle for endometrial preparation in Frozen-Thawed Embryo transfer cycles. AAMJ. Vol 13 (3). 2015. Suppl 1.

5. Cerrillo M, Herrero L, Guillén A, Mayoral M, García-Velasco JA(2017) Impact of Endometrial Preparation Protocols for Frozen Embryo Transfer on Live Birth Rates. Ram Maim medi J Apr 28; 8(2). doi: 10.5041/RMMJ.10297

6. Corroenne R, El Hachem H, Verhaeghe $\mathrm{C}$, Legendre G, Dreux C, Jeanneteau $\mathrm{P}$, Descamps P, May-Panloup P, and Bouet $\mathrm{P}(2020)$ Endometrial preparation for frozenthawed embryo transfer in an artificial cycle: transdermal versus vaginal estrogen. Jan 22. doi: $10.1038 / \mathrm{s} 41598-020-57730-3$

7. Samsami A, Chitsazi Z, NamaziG(2018) Frozen thawed embryo transfer cycles; A comparison of pregnancy outcomes with and without prior pituitary suppression by GnRH agonists: An RCT Int J Reprod BioMed 16 (9). 587-594, September.

8. Groenewoud ER, Cantineau AEP, Kollen B J,Macklon NS, and Cohlen BJ (2013)What is the optimal means of preparing the endometrium in frozen-thawed embryo transfer cycles? A systematic review and meta-analysis. Human Reprod Upd 19(5)458-470.

9. Testart J, Lassalle B, Belaisch-Allart J, Hazout A, Forman R, Rainhorn JD, et al(1986) High pregnancy rate after early human embryo freezing. Fertil Steril. 46:268-72.

10. Zhang L, Chen G, Liu P, Li M, Zhang J(1996) Cryopreservation of embryos in an IVF-ET program. Chin Med J 109: 631-4.

11. Van Royen E, Mangelschots K, De Neubourg D, Valkenburg M, Van de Meerssche M, Ryckaert G, , Eestermans W, Gerris J(1999) Characterization of a top quality embryo, a step towards singleembryo transfer. Hum Reprod. 14:2345-9.

12. Steer CV, Mills CL, Tan SL, Campbell S, Edwards RG(1992) The cumulative embryo score: a predictive embryo scoring technique to select the optimal number of embryos to transfer in in-vitro fertilization and embryo transfer program. Hum Reprod. 117: 7-9.

13. Hebisha SA, Omran MS, Sallam HN, Ahmed AI (2015) GNRH agonist treatment improves implantation of frozen thawed embryo transfer. Fertil Steril 104 (3) Supplement, Pages e271-e272.

14. Azimi Nekoo EA, Chamani M, Tehrani ES, Rashidi BH, Tanha FD, Kalantari V (2015) Artificial Endometrial Preparation for FrozenThawed Embryo Transfer with or without Pretreatment with Depot Gonadotropin Releasing Hormone Agonist in Women with Regular Menses. JFRH 9(1):1-4.

15. Hill MJ, Miller KA, Frattarelli JLA(2010) GnRH. agonist and Exogenous hormone stimulation protocol has a higher Live-birth rate than a natural endogenous hormone Protocol for frozen-thawed blastocyst-stage embryo transfer cycles: an analysis of 1391 cycles. Fertil Steril 93:416-22.

16. Davar R, Eftekhar M, Naeimeh T(2007) Transfer of Cryopreserved-Thawed Embryos in a Cycle 
Using Exogenous Steroids with or without Prior Gonadotropihin-Releasing Hormone Agonist. J Med Sci 7: 880-3.

17. Simon A, Hurwitz A, Zentner BS, Bdolah Y, Laufer N (1998) Transfer of frozen-thawed embryos in artificially prepared cycles with and without prior gonadotrophin-releasing hormone agonist suppression: a prospective randomized study. Hum Reprod 13: 2712-7

18. Dal Prato L, Borini A, Cattoli M, Bonu MA, Sciajno R,Flamigni C(2002) Endometrial preparation for frozen-thawed embryo transfer with or without pretreatment with gonadotropin-releasing hormone agonist. Fertil Steril 2002; 77: 956-60.

19. Pattinson AH, Green CA, Fleetham $J$ and Anderson-Skyes SJ (1992).Exogenous control of the cycle simplifies thawed embryo transfer and results in a pregnancy rate similar to that of natural cycles. Fertil Steril. 58:627-629.

20. Adams SM, Terry V, Hosie MJ, Gayer N, Murphy CR (2004). Endometrial response to IVF hormonal manipulation: Comparative analysis of menopausal, down regulated and natural cycles. Reprod Biol En $\neg$ docrinol 2: 21.

21. Glujovsky D, Pesce R, Fiszbajn G, Sueldo C, Hart RJ, Ciapponi A(2010) Endometrial preparation for women undergoing embryo transfer with frozen embryos or embryos derived from donor oocytes. Cochrane Database Syst Rev 20: CD006359.

22. Zhihong N, Yun F, Yijuan S (2008) Estrogen level monitoring in artificial frozen-thawed embryo transfer cycles using step-up regime without pituitary suppression: is it necessary? J Exp Clin Assist Reprod 5: 4.

23. Yang $X$, Dong $X$, Huang $\mathrm{K}$, Wang L, Xiong T, Ji L, Zhang $\mathrm{H}(2013)$ The effect of accompanying dominant follicle development/ovulation on the outcomes of frozen thawed blastocyst transfer in HRT cycle. Int J Clin Exp Pathol 6: 718-23.

24. Kalem Z1, Kalem M N, Gürgan T (2016). Methods for endometrial preparation in frozenthawed embryo transfer cycles ,J Turk G Gynecol Assoc.17:168-72.

25. El-Toukhy T, Coomarasamy A, Khairy M, Sunkara K, Seed P, Khalaf Y, et al. (2008) The relationship between endometrial thickness and out $\neg$ come of medicated frozen embryo replacement cycles. Fertil Steril 89: 832-9.

26. Richter KS, Bugge KR, Bromer JG, Levy MJ (2007) Relationship between endometrial thickness and embryo implantation, based on 1,294 cycles of in vitro fertilization with transfer of two blastocyst-stage embryos. Fertil Steril 87: 53-9.

27. Kumbak B, Erden HF, Tosun S, Akbas H, Ulug U, Bahçeci M(2009). Out $\neg$ come of assisted reproduction treatment in patients with endome $\neg$ trial thickness less than $7 \mathrm{~mm}$. Reprod Biomed Online 18: 79-84.

28. Queenan J, Ramey JW, Seltman HJ, Eure L, Veeck LL, Muasher SJ(1997) Transfer of cryopreservedthawed pre-embryos in a cycle using exogenous steroids without prior gonadotrophin-releasing hormone agonist suppression yields favorable pregnancy results. Hum Reprod 12: 1176-1180. 